\title{
El obispo Alonso Ramírez Granero de Ávalos y las repercusiones locales de su gobierno desde el Memorial de Bartolomé Álvarez. Charcas, 1578-1585
}

\author{
The Bishop Alonso Ramírez Granero de Ávalos \\ and the local repercussions of his government \\ from the Memorial of Bartolomé Álvarez. Charcas, 1578-1585 \\ Erick Figueroa Ortíz \\ Centro de Estudios Históricos \\ Universidad Bernardo O'Higgins-Chile \\ ee.figueroaortiz@gmail.com
}

\section{Resumen:}

Este artículo explora las repercusiones locales del obispo de Charcas Alonso Granero de Ávalos durante su gobierno entre 1578 y 1585. A través del memorial del clérigo Bartolomé Álvarez (1588), se destacan las actividades económicas del prelado y las medidas tributarias que instauró sobre la clerecía diocesana. Esta tendencia, a su vez, impactó en las parroquias indígenas como fuente de productos y mano de obra. Se propone, desde la denuncia y vida de Álvarez, cómo el gobierno del prelado impactó en la trayectoria de los clérigos, los conflictos desencadenados y las respuestas locales.

Palabras clave: Alonso Ramírez Granero de Ávalos; Bartolomé Álvarez; clero diocesano; doctrineros; Charcas.

\begin{abstract}
:
This article explores the local repercussions of the Bishop of Charcas Alonso Granero de Ávalos during his rule between 1578 and 1585. Through the memorial of the clergyman Bartolomé Álvarez (1588), highlighting the economic activities of the prelate and the tax measures that he established on the diocesan clergy. This trend, in turn, impacted on indigenous parishes as a source of products and labor. From the denunciation and life of Álvarez, it is proposed how the prelate's government impacted on the trajectory of the clergy, the unleashed conflicts and the local responses.
\end{abstract}

Key Words: Alonso Ramírez Granero de Ávalos; Bartolomé Álvarez; diocesan clergy; doctrineros; Charcas. 


\section{Introducción}

En 1588, el clérigo Bartolomé Álvarez firmaba como doctrinero en Aullagas un extenso escrito solicitando la intervención del Santo Oficio para frenar las idolatrías indígenas y sus cómplices hispanos. Esta solicitud no era inédita. El virrey Francisco de Toledo lo había sugerido contra de los “dogmatizadores" (p.e. Levillier, 1924, VI: 54), empero fue rechazado por incompatibilidades jurídicas, doctrinales y económicas (Recopilación, 1681, II: 192r; Medina, 1887: 17; Cunill, 2011; Domínguez, 2011), manteniendo el episcopado la jurisdicción en materia devocional indígena (Traslosheros, 2002; Cordero, 2016). Un año después de su redacción, se recibía el escrito en las oficinas de Felipe II, donde permaneció hasta que, a fines del sigloXIX, fue copiado para la sección de Inquisición del Archivo de la Corona de Castilla.

Diversos estudios han destacado la riqueza de contenidos del memorial. Principalmente, se han detenido en las prácticas indígenas descritas y los prismas del autor para describirlas (Martín Rubio, 1997, 2000; Villarías, 1998; Albó, 1999; Galdames y Álvarez, 2001-2002; Millones 2007; Regalado, 2008; Kermele, 2009; Battcock, 2015). En esta oportunidad, destacamos el aporte testimonial de Bartolomé Álvarez como observador y partícipe de los conflictos entre la jerarquía eclesiástica y los clérigos doctrineros en el obispado de Charcas, especialmente en el campo económico. Nos enfocaremos la mirada en las acciones del obispo Alonso Ramírez Granero de Ávalos, contemporáneo de Álvarez en su primera etapa como doctrinero, a fin de subrayar las repercusiones económicas de su gobierno en las parroquias rurales.
Las expectativas y actividades económicas de doctrineros y autoridades eclesiásticas en el virreinato peruano se propagaron tempranamente. Al avanzar la construcción del sistema parroquial en los Andes, fueron constantes las denuncias de abusos económicos perpetrados por eclesiásticos. Estos "abusos" deben ser leídos como formas de apropiación que dispusieron los doctrineros para obtener parte del producto y servicio indígena (Lavallé, 1982; Acosta, 1982). Para lograrlo, mantuvieron con los grupos indígenas un equilibrio de beneficios mutuos, conjugando labores pastorales y rearticulaciones indígenas en materia de autoridad y devoción (Duviols, 1977: 401; Monsalve, 2003; Marsilli, 2005; Hidalgo, 2011; Hidalgo et al. 2016; Morrone, 2017). Algunos eclesiásticos aprovecharon la actividad pastoral para obtener excedentes económicos y/u ocupar mejores cargos, siempre en sintonía con el contexto en el que se desenvolvían. Estudios sobre figuras destacadas dentro de la carrera eclesiástica del virreinato peruano como Cristóbal de Albornoz, Francisco de Ávila y Francisco de Otal o el primer arzobispo de Lima, Jerónimo de Loayza, han evidenciado estas estrategias (Acosta, 1987, 2016; Ramos, 1991; Guibovich, 1991; Hidalgo, 2011).

En sintonía con ello, el obispado de Charcas durante la década de 1580 vivió un auge económico importante empujado por la producción de plata en Potosí, lo que incentivó los intereses de los eclesiásticos. Los planes toledanos comenzaban a dar frutos, especialmente la introducción del azogue y la constante circulación de población a través de la mita (Bakewell, 1989; Quisbert, 2015). Esto dinamizó económicamente no solo el centro minero, sino que a todo el virreinato 
en un continuo flujo de metálico, mercancías y mano de obra (Assadourian, 1982). Elobispado era extenso y a la vez rico, lo que elevaba las expectativas, precios e ingresos del cuerpo evangelizador (Pérez, 2013: 17).

En consecuencia, este artículo explora las repercusiones locales del obispo de La Plata Alonso Granero de Ávalos durante su gobierno, entre 1578 y 1585 . A través del memorial del clérigo
Bartolomé Álvarez (1588), se destacan las actividades económicas del prelado y las medidas tributarias que instauró sobre la clerecía diocesana. Esta tendencia, a su vez, impactó en las parroquias indígenas como fuente de productos y mano de obra. Se propone, desde la denuncia y vida de Álvarez, examinar cómo el gobierno del prelado impactó en la trayectoria de los clérigos, los conflictos desencadenados y las respuestas locales.

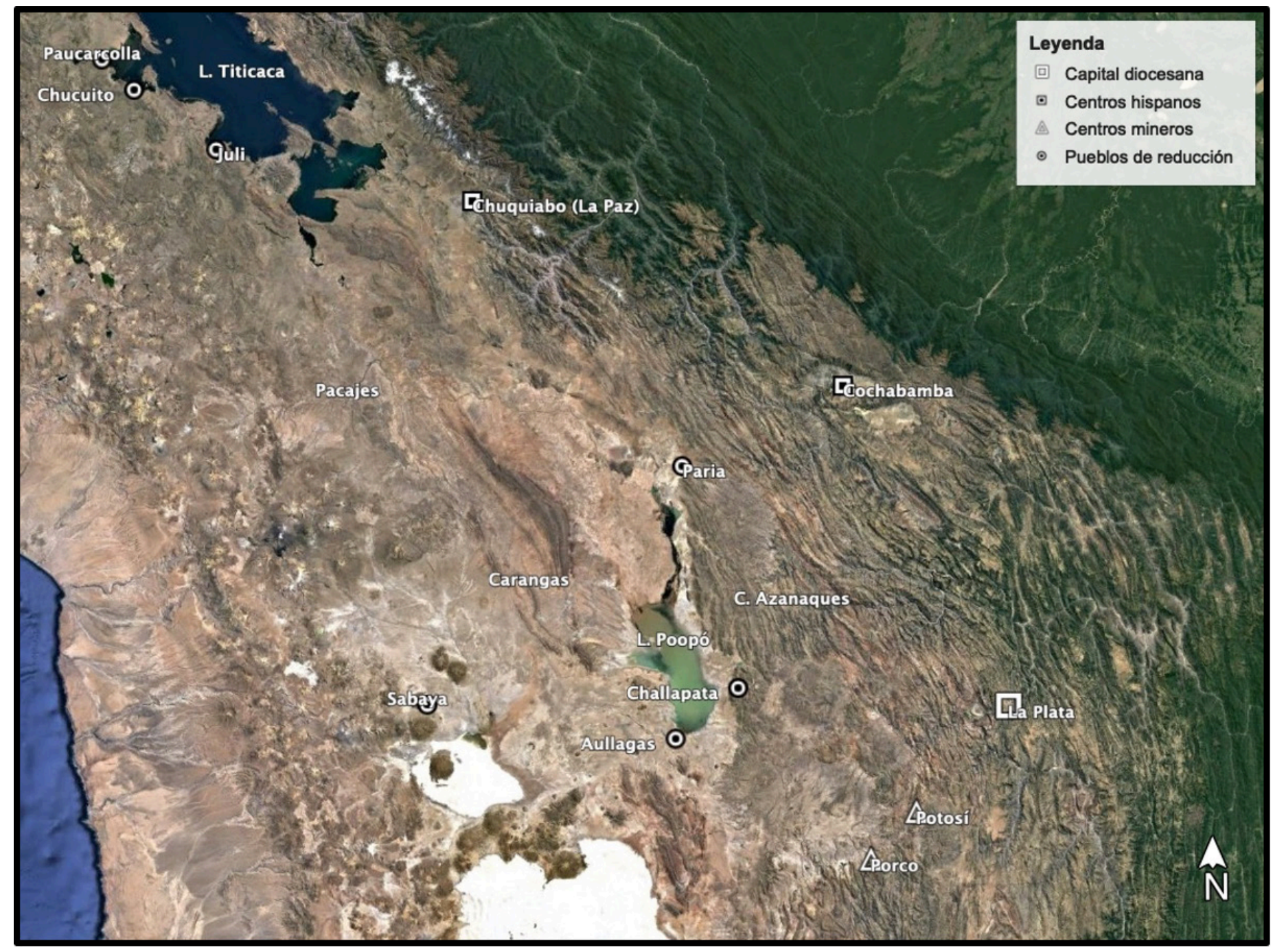

Mapa 1. Sectores de la diócesis de Charcas mencionados en este artículo. Elaborado en Google Earth 
Se constata que la corta estadía del prelado no pasó desapercibida en Charcas, diócesis que se caracterizó por largos periodos de acefalía y tutela del Cabildo Eclesiástico: solo cuatro obispos tomaron la mitra entre la fundación del obispado en 1553 y 1594, cuando se comienza a regularizar la presencia efectiva de la autoridad obispal con Alonso Ramírez de Vergara (Castro, 2021). Se ha destacado la participación del obispo Granero de Ávalo en el Tercer Concilio como representante de la diócesis, el apoyo a su par del Cuzco Sebastián de Lartaún en los conflictos contra el arzobispo Toribio de Mogrovejo y su breve participación en las apelaciones a los decretos conciliares (Vargas Ugarte, 1954: 66, 76; García, 1964: 99; Querejazu, 1995: 86). Pérez (2013) ha dedicado un apartado analizando su impronta personalista y defensa de la autoridad obispal. Vargas Ugarte planteó que la actitud y conducta del obispo Alonso Ramírez Granero impiden otorgarle "un cumplido elogio" (Vargas Ugarte, 1954: 67). García (1964), al contrario, destaca su "pobreza de vida, a pesar de sus cuantiosas rentas que las invertía en limosnas" (99). En el presente estudio se aportan otros antecedentes y perspectivas para analizar su estadía en Charcas.

El recorrido comienza por los antecedentes del obispo Granero de Ávalos camino a Charcas. Indaga en sus intereses económicos, actividad como gobernador de la diócesis, roces con la Audiencia y decisiones económicas. Finalmente, se expondrá el testimonio de Álvarez, subrayando las repercusiones locales y los conflictos que obstaculizaron su trayectoria como cura doctrinero.

\section{Actividades económicas de Alonso Ramírez Granero de Ávalos camino a Charcas}

Natural de Villaescusa de Haro, se embarcó a Nueva España en 1573 nombrado como juez del Santo Oficio, tras experiencias previas como prebendado en Guadix y fiscal inquisidor en Llerena (Vargas Ugarte, 1954: 66)[1]. Para el viaje solicitó transportar con facilidades tributarias 800 pesos en joyas de oro y plata, tres eslavos "libres de derechos", seis criados, seis mujeres y "dos armas de cada género" - defensivas y ofensivas (RAE, 1726: 391)[2].

La presencia de Granero de Ávalos en Nueva España fue polémica. Por una parte, la actividad del Inquisidor fue bien recibida por las autoridades civiles de Guadalajara, quienes en 1576 lo recomendaron para ocupar la mitra del fallecido prelado[3]. Por otra, sembró fama de avaro y codicioso, ya que, aun siendo rico, "dejó cosas sin pagar" (Vallejo, 2001: 229).

Irigoyen (2008) ha destacado cómo las autoridades episcopales actuaron de acuerdo con el aumento del patrimonio familiar, sostén de la carrera eclesiástica, motivación nuclear en la movilidad social y guía en la actividad económica. Granero de Ávalos refleja esta tendencia. Los antecedentes sobre sus actividades antes de ocupar el obispado de Charcas dan cuenta del interés económico tras sus decisiones, complementando el patrimonio económico familiar desde su posición.

Antes de salir de México, camino a Charcas, Ávalos compró un navío a Jacome Corzo, mercader limeño, con el que pretendía llevar brea a Nicaragua, 
aprovechando la alta demanda del alquitrán. La compra se realizó por intermedio de su sobrino, Alonso de Ávalos. No obstante, el negocio implicó un gran coste para el obispo, quien acusó engaños y repartió penas de excomunión contra los involucrados (Vallejo, 2001: 229-231).

Estando aun en México, el recién nombrado obispo Granero de Ávalos comenzó gestiones en el Consejo de Indias para obtener ingresos económicos por dos vías. Una de ellas es el compromiso de pago por ejercer como Inquisidor al zarpar de Nueva España, cargo que no le correspondía oficialmente tras su nombramiento como obispo. Aunque fue aprobado por el Consejo de Indias en primera instancia (1581), se suspendió dos años después ante los reclamos del Tribunal de Nueva España y de la Real Hacienda (Vallejo, 2001: 234) [4].

A mediados de 1580 recaló en la provincia de Nicaragua, instrumentalizando su autodesignada protestad inquisitorial para satisfacer intereses económicos y mercantiles, ejecutando autos de fe en visitas itinerantes contra quienes criticaban su actuar (Vallejos, 2001: 221). Además, zarpó de la provincia "sin pagar algunas cosas que quedó debiendo" (Medina, 1952: 103). Respondiendo a la queja formal presentada por la Inquisición de México acusando la usurpación jurisdiccional[5], en su defensa elaborada en 1582 desde Arequipa, el obispo acusó haber sido engañado e insistió en el carácter oficial de actividad y los beneficios que implicó para la ortodoxia (Medina, 1952: 104; Vallejos, 2001: 233).

Otra vía de ingresos económicos que gestionó Granero de Ávalos fue la solicitud del pago por los "frutos" del obispado de La Plata durante el tiempo de sede vacante y su nombramiento como obispo, entre 1574 y 1578. Este dinero, que la cédula menciona como "cuarta de pago", se debía distribuir entre él y el edificio de la catedral. Felipe II accedió en diciembre de 1578, "atento a que estaba necesitado", debiendo estar disponible en cuando llegase el prelado a su diócesis (García, 1964: 102; Enciso, 2005: 365). Se debe mencionar que la "cuarta" fue un concepto fiscal ambiguo. En este caso, Granero de Ávalos debió apelar a la interpretación como porción canónica, es decir, asegurar la cantidad de dinero que pertenecía al obispo proveniente de los bienes dejados por los deudos en sus iglesias para el bien de sus almas (André et al., 1847-1848: 380-381; Sala, 1858: 116, 269-270). Como se verá, esto se tradujo en un impuesto a las rentas eclesiásticas solventado por las parroquias rurales.

\section{Las medidas económicas durante el gobierno del obispo Granero de Ávalos}

El obispo llegó en mayo de 1582 a La Plata, cuatro años después del nombramiento (García, 1964: 99; Querejazu, 1995: 87)[6]. Por su testamento, sabemos que arribó a la diócesis con 42 mil pesos en “joyas y preseas" (Levillier, 1922, II: 297), bastante más que los 800 pesos declarados en Sevilla hacia 1573. Las riquezas adquiridas fuera de su cargo eclesiástico habían aumentado a manos de su sobrino, Alonso de Ávalos, quien labró para él "las estancias que el virrey [...] don Martín Enrique le dio [...] en la Nueva España” (Levillier, 1922, II: 297). 
Una vez en Charcas, el obispo se hizo sentir en los espacios de poder relacionados con la designación de curas en beneficios eclesiásticos para generar redes en zonas rurales. Esto le llevó a entrar en conflicto con el otro cuerpo encargado del Patronato Regio, la Audiencia (Enciso, 2005: 382). El seminario tridentino fue un espacio disputado por Granero de Ávalos, muestra de su intento por "restablecer la autonomía y jurisdicción" obispal en la formación y certificación de los curas tras varios años de sede vacante (Pérez, 2013: 16). Para acelerar la apertura del seminario y blindar la dependencia de la institución al obispo, activó el impuesto a las rentas eclesiásticas, acorde a las constituciones del Concilio de Trento (1545-1563), para su sustento (López de Ayala, 1785[1564]: 360; Pérez, 2013: 25).

En contraparte, la Audiencia denunciaba en febrero de 1585 que el obispo intentaba ser "señor absoluto de las doctrinas", designando “paniaguados y domésticos" para beneficio propio sin respetar la cédula de 1581 sobre patronato regio. Los curas tomaban parte de sus planes, procurando "tener propicio al obispo pues con sola su aprobación esperarían ser proveídos" (Levillier, 1922, II: 171). La denuncia de la Audiencia muestra que el obispo logró asentarse de buena forma entre algunos clérigos, estableciendo relaciones interpersonales con los candidatos a ser doctrineros.

Granero de Ávalos fue parte del proceso de secularización vivido en las Indias, tras la recepción de una cédula que priorizaba la designación de clérigos en las doctrinas por sobre los regulares (Vargas Ugarte, 1959: 208; Piho, 1977; Álvarez, 2015). Sin embargo, diversas quejas retrotrajeron la decisión de Castilla en 1588 (Encina, 1945[1596], I: 99, 101). En este proceso, el obispo aprovechó la oportunidad para insertar aliados entre las doctrinas. Así lo denunciaba la Audiencia de Charcas, mostrando preocupación ante la escasa presencia de religiosos doctrineros: 20 de 150 beneficios (Levillier, 1922, II: 172). Para llevar a cabo este proceso, acusaba la autoridad civil que el prelado impulsó violentamente la toma de los cargos, "procediendo de hecho y con mano armada los clérigos a quien envió a ejecutar sus mandamientos". Afectada, la Compañía de Jesús solicitó la retribución y suspensión del estipendio a los clérigos recién llegados (Levillier, 1922, II:171-172).

En 1582, el obispo Granero de Ávalos es convocado al Tercer Concilio en la capital del arzobispado. En este evento declaró haber gastado de su propio peculio 40 mil pesos (Levillier, 1922, II: 303), arribando tardíamente en compañía del obispo de Tucumán Francisco de Vitoria (Vargas Ugarte, 1954: 64). En este encuentro, Ávalos fue parte activa de los conflictos surgidos contra el arzobispo Toribio de Mogrovejo, aliándose con Sebastián de Lartaún, obispo del Cuzco, acusado de actividades económicas, presiones y violencia contra los clérigos doctrineros (Vargas Ugarte, 1954: 67). Como juez compromisario, Granero de Ávalos absolvió a Lartaún de los cargos imputados durante el Concilio (Pérez, 2013: 22), y, bajo esta amistad, sentenció a favor de Cristóbal de Albornoz, liberándolo de acusaciones en su contra (Guibovich, 1991: 216; Millones, 2007: 324).

En octubre, antes de dejar Lima, los obispos participantes firmaron un decreto que protegía 
el fuero de los prelados en torno a las censuras acordadas por las reuniones conciliares limeñas de 1567 y 1583, distanciándose de los doctrineros. El jesuita Joseph Acosta acusó no haber visto el documento en su labor de secretario (Vargas Ugarte, 1952: 194). Empero el documento fue firmado por el arzobispo de Lima y obispos de La Imperia, Santiago, Tucumán y Charcas (Levillier, 1922, II: 252).

En su retorno a La Paz, Granero de Ávalos no logró publicar las constituciones acordadas por mandato de la Audiencia, que exigió la correspondiente revisión del Consejo de Indias (Recopilación, 1681: 42r; Levillier, 1922, III: 174). Un año después de finalizada la reunión episcopal, participó en la elaboración y planificación de las apelaciones contra los decretos del Concilio. Esta delegación tuvo como objetivo principal apelar a las penas de excomunión mayoripsofacto, núcleo de la reforma para controlar a los doctrineros. En la recopilación que realizó Diego de Almeyda en 1593 para solicitar el pago de las remuneraciones y premios acordados como procurador jefe, se encuentran los resultados de las presentaciones en Madrid y Roma, esta última a cargo de Francisco Estrada.

Antes de escoger al procurador, se elaboraron en Potosí, La Plata y La Paz tres instrucciones que fueron condensadas en una "Instrucción General" el 8 de octubre de 1584. En presencia del obispo se acordó apelar a las penas de excomunión, mejorar las condiciones laborales de los clérigos doctrineros, obtener mayores atribuciones económicas y administrativas y quitar la presencia de intermediarios entre clérigos e indígenas, como frailes y corregidores. Destaca la solicitud para conceder beneficios eclesiásticos a perpetuidad y mayores atribuciones para castigar a los indígenas, quienes mantenían pecados carnales e idolatrías "habiendo ya pasado el tiempo en que se les con[ce]dio gracia y privilegio" [7]. Para financiar la misión, se impuso como medida económica entre los clérigos la obligación de "dar respecto de cada doctrina treinta pesos ensayados por salario e ayuda de costa [...] que por todo rigor de derecho sean compelidos a cumplir" [8]. El papel de los representantes locales que asistieron a esta reunión debió asegurar el compromiso del conjunto de doctrinas que representaban, lo que, como veremos, no estuvo exento de consecuencias importantes para los clérigos doctrineros.

El 4 de enero de 1585 se llevó a cabo la reunión que definió al representante del clero. Granero de Ávalos participó como procurador subrogante de las provincias de Cochabamba, Porco y Lipez, junto a los de Charcas (La Plata), Chucuito, Carangas, Paucarcolla y el vicario subrogante de los Pacajes. Hubo cuatro candidatos posibles, quienes debían acreditar un piso económico que les permitiera cobrar los gastos a su retorno. El primer escogido fue Diego de Alarcón, administrador del obispado, pero, declinó por estar realizando una visita y "confirmación del obispado". Su lugar fue ocupado por Domingo de Almeyda, quien aparece con cargo de visitador y, por tanto, delegado del obispo. En tercer y cuarto lugar se consideró al bachiller Iñigo de Aguirre, vicario de Chucuito y al licenciado Gabriel Solano. Almeyda aceptó tres días después[9], retornando como canónigo de Charcas una vez finalizada la misión (Pérez, 2013: 22). 
Estas diligencias prolongaron la confirmación del Concilio hasta 1591, cuando Felipe II firmó el texto final. A pesar de la apelación, el monarca cuatro años antes había asegurado la validez de los decretos. En el obispado de Charcas, sin embargo, recién en 1594 se publicaron las constituciones de la reunión episcopal, manteniendo las disposiciones del Concilio de Trento y el Segundo Concilio Limense de 1567 como referentes normativos durante el periodo (Castro, 2021). Las instrucciones del clero se materializaron en 14 cédulas, dirigidas mayormente al virrey y audiencias, con el objetivo de regular las actividades que tocaban el ámbito eclesiástico y económico en las doctrinas[10].

El obispo Granero de Ávalos no vio el resultado de la apelación, falleciendo en La Paz en noviembre de 1585. La Audiencia informaba al Rey en enero de 1586 que le solicitó al prelado volver a la catedral una vez finalizado el Concilio. Sin embargo, hizo caso omiso, encargándose de un altercado que involucraba a algunos "clérigos y ordenantes" contra "un hidalgo que allí residía [...] por le haber recusado con palabras indecentes en cierta causa que en su audiencia episcopal trataba" (Levillier, 1922, II: 209).

En su testamento del 13 de noviembre de 1584, seis días antes de morir, Granero de Ávalos repartió sus bienes a obras pías, parientes y oficiales bajo su tutela. Cabe destacar el reconocimiento del obispo hacia sus familiares, tanto en Charcas como en España, lo que se explica por la colaboración y fortalecimiento del patrimonio familiar (Irigoyen, 2008). Como albaceas designó a su prima hermana Sancha de Ávalos y Toledo, su sobrino
Alonso de Ávalos, el fiscal Francisco Ruano Tellez y el vicario Juan Osorio. De los bienes traídos de Nueva España, estipuló dineros para adquirir "una memoria" en su natal Villaescusa, con un capellán y apoyo a cuatro "estudiantes pobres". Su sobrino Alonso de Ávalos recibió una parte de estos bienes por aumentar el patrimonio del obispo (Levillier, 1922, II: 297-298). Además, le nombraba “patrón” de la memoria, designando, además, a otros familiares como suplentes (Levillier, 1922, II: 300). También, destinó recursos a personas e iglesias pobres del obispado, deudos y criados "que se han de premiar conforme a su servicio" (Levillier, 1922, II: 303). Su prima hermana Ávalos de Toledo recibió cuatro mil ducados "por la cuenta e administración que ha tenido de nuestra casa" (Levillier, 1922, II: 303). Tres días después testó los bienes adquiridos como obispo -in intuitu eclesiae- en tres limosnas por partes iguales: para las “parroquias e doctrinas pobres”, según lo estipulen sus albaceas; para los hospitales de La Plata, La Paz y Cochabamba; y para familiares, ayudantes traídos de México y pago de remuneraciones (Levillier, 1922, II: 304-307).

Tiempo antes de morir, algunos "clérigos y criados" entraron a su casa en La Paz "robando todo cuanto tenía y se entiende ser mucha suma" (Levillier, 1922, II: 209). Dos años después, el licenciado Hernando de Lopidana detallaba que Granero de Ávalos tenía en La Paz “doce mil pesos en monedas, joyas y demás arreos de casa y esclavos los cuales bienes tomaron y usurparon [cuatro o cinco días antes de morir] sus deudos y criados [...] los más de todos clérigos”. Además, el mismo día de su fallecimiento, cuatro de sus criados sacaron bienes a escondidas, aludiendo 
que el obispo había proveído que se repartiesen sus enseres antes de morir (Levillier, 1922, II: 290).

En La Plata, una vez conocido el deceso de Granero de Ávalos, los administradores de su hacienda escondieron "mucha hacienda y entre ella preseas de mucho valor y cosas conocidas" antes que llegasen los oficiales de la Audiencia. Las diligencias permitieron recuperar "joyas [...] cosas de ropa y camas de seda y alguna plata labrada". Las informaciones sobre sus bienes, además, ilustran la extendida presencia económica del obispo en la diócesis, manejando mercancías estratégicas como vino, coca, textiles, mulas y ganado "en un pueblo de indios doce leguas de La Plata y en otras partes carneros de Castilla y deudas y otros dares y tomares en todo el distrito". La Audiencia calculaba la hacienda del obispo en más de $100 \mathrm{mil}$ pesos. Sin embargo, se había encontrado solo 35 mil pesos, que no alcanzaban a saldar todas las solicitudes de pago surgidas tras su fallecimiento (Levillier, 1922, II: 290-291).

El largo recorrido anterior devela que la actividad del obispo Ávalos, en tres años de gobierno, no pasó desapercibida. En un obispado que incrementaba los flujos de mercancías, quiso hacer valer su autoridad e influencia, manejando las designaciones de doctrineros y tomando medidas para saciar sus expectativas económicas y políticas con ayuda de sus familiares. Proponemos que el testimonio del clérigo Bartolomé Álvarez refleja cómo las actividades económicas del prelado afectaron a las parroquias indígenas y sus doctrineros.

\section{Pensamiento y actividades económicas del clérigo Bartolomé Álvarez}

Los escasos datos sobre la vida de Bartolomé Álvarez son conocidos principalmente por la información que aportó el equipo editor del memorial (Villarías y Martín Rubio, 1998: XIII). Natural de Santiago de Compostela, se graduó de Bachiller en Leyes en la Universidad de Salamanca a los diecisiete años, en 1557. Estuvo en Roma, donde menciona haber conocido al papa Pío V (regente entre 1566 y 1572) y haber visto a Juan de Zúñiga Requeséns, quien ocupó la embajada hispana de la capital cristiana entre 1568 y 1579.

Según sus palabras, no ocupó una capellanía en España por temor a "la carga" que implicaba ser cura de almas (Álvarez, 1998[1588]: 58). Según Morgado (2000), los titulares en parroquias hispanas tenían un acceso no menor a réditos estables, influencias dentro de la feligresía y, según las características del clérigo, posibilidades de ascenso.

Sin embargo, Bartolomé Álvarez escogió la diócesis de Charcas como destino respondiendo a un interés económico. El auge económico del obispado atraía a los pretendientes de prebendas. No era el único. Estas expectativas de los pastores fueron ampliamente denunciadas por las autoridades civiles y eclesiásticas, quienes solicitaban mayores filtros desde la península y facultades de certificación sobre los designados en las doctrinas (Levillier, 1922, III: 48; Pease, 1969: 109; Suess, 2002: 170). En 1591, la Audiencia de La Plata denunciaba: 
la causa de venir tanto clérigos a este obispado es la general de todos los que vienen de España que acuden a labor deste cerro rico de Potosí y grosedad de esta provincia más que a las otras de este reino (Levillier, 1922, III: 129).

El clérigo Álvarez se incluía en esta tendencia: “y como todos venimos con este desdichado deseo de adquirir algo con que volver a descansar a nuestras tierras [...] antes todos las aumentan, aunque sea a costa de pobres". No obstante, denunciaba que las autoridades civiles y eclesiásticas no dejaban espacio a los clérigos para obtener ingresos. En consecuencia, "forzoso es haber descomposición en el clero", destacando la frustración e iniciativa de algunos doctrineros para obtener ingresos extra (Álvarez, 1998[1588]: 490).

Al momento de escribir el memorial, entre $1587 \mathrm{y}$ 1588, Álvarez menciona haber estado doce años en Charcas. Su arribo se produce aproximadamente en 1576. Con esta cantidad de años, el clérigo había cumplido un piso mínimo de permanencia exigida por las autoridades civiles (Levillier, 1922, III: 48), lo que pudo ser un motivo extra para diseminar acusaciones y explicitar actitudes disonantes con la legislación.

El primer rastro de Bartolomé Álvarez en La Plata es una obligación de pago que compartió con Luis Delgado en favor de Francisco Martínez, el 30 de noviembre de 1579[11]. Esta información confirma su presencia en la diócesis a fines del gobierno de Francisco de Toledo, su iniciativa económica y las redes en las que pudo haber participado.
El trabajo pastoral de Álvarez habría comenzado en los bordes del lago Titicaca, ocupándose de grupos lupaca en Juli y Chucuito (Álvarez, 1998[1588]: 217). Desde noviembre de 1576, Juli estaba a cargo de los jesuitas por influencias del virrey Toledo, transformándose en un importante lugar para el estudio evangelizador y aprendizaje de lenguas indígenas. A su vez, por críticas a la gestión de los dominicos, Chucuito y otros seis pueblos pasaron a manos de clérigos (Querejazu, 1995: 73-74). La presencia del clérigo allí pudo obedecer al aprendizaje de las lenguas indígenas debido a la enseñanza que ofrecía el reducto jesuita (Querejazu, 1995: 74), cumpliendo el requisito lingüístico para ejercer como doctrinero de indios (Encina, 1945[1596], I: 98).

Paralelo a su labor y quizá en el mismo periodo, buscó entre la cordillera de Chuquiabo (La Paz) "minas de oro de gran fama, que los curacas de aquella tierra tienen ocultadas" (Álvarez, 1998[1588]: 383). También estuvo "unos pocos días [de] cura en Potosí” (Álvarez, 1998[1588]: 355), cumpliendo con la obligación toledana de acompañar a los feligreses mitayos que se dirigían al Cerro Rico o sus chácaras (Cook, 1975). Álvarez dedicará páginas en su memorial para resaltar la perversión de Potosí y las riquezas minerales del obispado, ávidas de mayor explotación (Álvarez, 1998[1588]: 382).

El testimonio de Álvarez deja en claro que la ortodoxia le trajo conflictos con todas las poblaciones indígenas, cerrando las posibilidades de negociación para concretar sus expectativas e intereses. Por lo visto, el clérigo no logró adecuarse a la lógica que imperó en las doctrinas, 
siendo importantes espacios económicos para los hispanos y en especial para los eclesiásticos.

Ante las prohibiciones de la Corona (Encina, 1945[1596], I: 122), y del Segundo y Tercer Concilio Limense (Vargas Ugarte, 1951: 239, 243; Lisi, 1990: 167), la intervención económica de los doctrineros se basó en la capacidad para establecer relaciones locales con los líderes étnicos y sus súbditos. Favorecidos por la autonomía de las parroquias lejanas, los doctrineros abusaron del pago por servicios religiosos, dispusieron de mano de obra indígena y comercializaron productos de las poblaciones nativas para beneficio personal (Lavallé, 1982; Acosta, 1982). En sintonía con otros intereses interrelacionados dentro de un "sistema de complicidades" (Duviols, 1977: 401) cada agente colonial puso en juego sus espacios de poder para lograr un equilibrio de beneficios mutuos. Sin embargo, cuando este se rompía, comenzaban las acusaciones cruzadas contra la labor del doctrinero y la cristiandad de los indígenas (Monsalve, 2003; Hidalgo, 2011; Marsilli, 2005; Morrone, 2017).

En cambio, Bartolomé Álvarez trató de matizar las críticas hacia las actividades económicas de los clérigos, aunque reprochaba la acumulación económica a fin de obtener "amigos" entre las autoridades eclesiásticas (Álvarez, 1998[1588]: 52, 340-341). Para él, la comercialización de productos era parte de los beneficios que otorgaba dirigir una parroquia (Álvarez, 1998[1588]: 69). Sin embargo, era crítico de la venta de hoja de coca, elemento devocional indígena muy difundido, denunciando la preponderancia que tenía aquel arbusto en las rentas eclesiásticas del obispado
(Álvarez, 1998[1588]: 377). En forma global, el aumento de patrimonio no fue tradicionalmente ajeno a los eclesiásticos, aunque sí había una penalidad cuando se caía en usura, negligencia pastoral y avaricia (Le Goff, 2013). En opinión del clérigo Álvarez, las actividades económicas en manos de eclesiásticos no eran un mal ejemplo para los nuevos feligreses, como lo proponían las autoridades episcopales (Vargas Ugarte, 1951: 345; Lisi, 1990: 167), más bien, eran un elemento de integración a la policía hispano-cristiana, fundamental para superar un estado anterior de sobrevivencia material "trocando cosas por cosas” (Álvarez, 1998[1588]: 69).

Para Álvarez la remuneración sacerdotal en el obispado de Charcas-en promedio 800 pesos por doctrinero (Cook, 1975)-, no alcanzaban a cubrir lo básico de la dignidad del oficio. Por tanto, era necesario autorizar la obtención de ingresos extra, pues "en el sonido [los sínodos] parecen opulentos, [y] no lo son sino muy tenues" (Álvarez, 1998[1588]: 51). Destacaba los precios de bienes cotidianos para la vida en el obispado, el quehacer sacerdotal y los recurrentes procesos judiciales como obstáculos para acumular peculio o apoyar económicamente a parientes con problemas:

Pues si de salario gana mil y ochocientos pesos corrientes, ¿qué le quedará para remediar el suceso de enfermedades a que están sujetos? ¿Hay alguno que pueda vivir sin tener cabalgaduras, sin vestir ni calzar y tener algún extraordinario? Aunque más guarde, no se puede guardar todo. ¿Hay alguno tan solo que no tenga en Castilla padre, madre o hermanos, o avieso-que no son muy ricos-, 
a quien deban y deseen socorrer? (Álvarez, 1998[1588]: 51)[12].

\section{Las repercusiones locales del obispo Granero de Ávalos: el testimonio de Bartolomé Álvarez}

En su texto, Bartolomé Álvarez describe algunos impactos provocados por la llegada del obispo Granero de Ávalos y los intentos del prelado para vincularse económicamente con las parroquias indígenas:

Fue el obispado del obispo don Alonso Granero de Ávalos tan lleno de obispo que no había en todo su obispado casa o rincón, ni aun en los desiertos inhabitables, que no estuviese lleno de su poder, como si fuera su ser deífico (Álvarez, 1998[1588]: 53).

Esta predisposición económica del obispo tuvo una buena acogida entre los miembros de la diócesis, destacando el intento de algunos por acercarse al prelado:

cuando entró en su obispado, [Granero de Ávalos] conoció que de miedo se le sometían [los clérigos] como gente de poco valor, por las dolamas que todos tenían, queriéndole captar la benevolencia con dones; por donde conoció la tierra y la usanza della, y así los vino a tratar, de suerte que les hacía estar delante de sí en pie y destocados, como lacayos (Álvarez, 1998[1588]: 61)[13].

Las visitas eclesiásticas fueron importantes instrumentos tridentinos de control y diseminación de la autoridad episcopal (Cadau, 1998), ya que, estrecharon los lazos verticales del poder y fomentaron espacios de negociación entre distintos intereses locales (Ramos, 2016, 2019). Como forma de acercarse a las parroquias indígenas, el clérigo Álvarez menciona que el obispo realizó seis visitas, cinco comandadas por representantes y una personal cuando se dirigía al Tercer Concilio (Álvarez, 1998[1588]: 49, 50, 60, 195). Estas se destacaron, según Álvarez, por su carácter conflictivo, sin lograr la obediencia que pretendía el obispo.

Una de ellas, realizada entre la cordillera de los Azanaques y la cuenca del lago Poopó, tuvo como protagonista el conflicto entre dos visitadores que se disputaban la titularidad de la fiscalización. Al adelantarse uno, el rezagado, enviaban excomuniones "llamando [a] los clérigos para que el primer visitador no les hallase en sus casas". El conflicto decantó localmente en Challapata, donde el clérigo doctrinero Juan de Escobar "hubo de contentar a los dos [...] dando lo que no debía a la sedienta codicia" (Álvarez, 1998[1588]: 49).

Según Álvarez, la visita personal que realizó Granero de Ávalos durante su trayecto al Tercer Concilio junto a su par del Tucumán no tuvo una buena recepción entre los doctrineros, en parte, por la codicia del prelado y por el intento de los clérigos para evitar las fiscalizaciones. Al llegar a Aullagas, encontraron vacía la doctrina. El clérigo titular, Juan González, no había realizado su labor pastoral de buena manera por ocuparse de sus "enfermedades [...] unas de codicia y otras naturales" $\mathrm{y}$, al verse amenazado, como otros, se fugó del pueblo por miedo al castigo y "sed" del obispo (Álvarez, 1998[1588]: 195): 
Porque, si el [obispo] de los Charcas procurara de tener sacerdotes de entendimiento y hábiles para que le descargaran la conciencia -y no colmenas que castrar tres o cuatro veces cada año, que era cosa incompatible-, y los tratara con amor, como hombres que llevan la carga -que los obispos y la sede vacante no llevan, ni las Audiencias ni otros, y los sacerdotes no sólo llevamos la carga sino hiel amarga con ella, en lugar de paga-, no se le huyeran los que era razón que le esperaran y hospedaran. (Álvarez, 1998[1588]: 196).

Otra visita fue suspendida tras el fallecimiento delobispo (Álvarez, 1998[1588]: 60), posiblemente a cargo del administrador del obispado y deudo de Ávalos, Diego de Alarcón (Levillier, 1922, II: 305) [14].

Como parte de sus medidas tributarias, en una de sus visitas Granero de Ávalos subió de 10 a 30 pesos el impuesto que pagaban las iglesias por pila bautismal. Álvarez mencionaba que, cuando una pila era compartida por dos iglesias, se cobraba el doble (Álvarez, 1998[1588]: 46). Esta decisión, la que debía ser saldada por las arcas de la parroquia y sus feligreses, pudo aumentar la presión económica en las doctrinas, especialmente a expensas de la relación entre el doctrinero y sus feligreses.

La actividad comercial del obispo es mencionada por Álvarez en su texto, ofreciendo información importante sobre ella, y a los familiares que involucraba. Esto confirma una tendencia de Granero de Ávalos para planificar y mantener un ritmo económico similar a las pautas que desarrolló en México.
Para Álvarez, los obispos de Charcas y Cuzco era buenos ejemplos de cómo los familiares intervenían en la vida económica de las diócesis y designaciones eclesiásticas, respaldados por la autoridad del prelado. El clérigo solicitaba mayores filtros en la designación de obispos casados (Álvarez, 1998[1588]: 55-56). Como se mencionó, Granero de Ávalos llegó a Charcas con algunos familiares, entre ellos su prima hermana Sancha de Ávalos y Toledo y su sobrino Alonso de Ávalos, actores importantes del basamento económico del obispo. Álvarez recoge rumores sobre la supuesta relación como esposa e hijo del obispo. Sin embargo, no disponemos de documentación que aclare si el obispo Ávalos contrajo matrimonio o si tuvo descendencia.

Una actividad económica del obispo Granero de Ávalos era el repartimiento de mercancías a los clérigos doctrineros para ser transportadas y vendidas entre sus feligreses indígenas. Esto recuerda el extendido mecanismo económico utilizado por autoridades hispanas para presionar económicamente a las comunidades indígenas en los siglos XVII y XVIII (véase O’Phelan, 1988; Carmagnani, 2004). Álvarez acusaba la preeminencia de Alonso de Ávalos, su "hijo”, en las actividades comerciales del obispo. Como vimos, el testamento del obispo dejaba claro que Alonso, como sobrino del obispo, se había ocupado de administrar y aumentar los bienes de Granero de Ávalos en México. Esta tarea debió seguir en Charcas. Álvarez denunciaba que la amenaza era parte del negocio, aunque, probablemente hubo clérigos que deliberadamente accedieron a la red comercial. Citamos en extenso el escrito del clérigo: 
[...] también ocupaba la tierra un "sobrino" -o hijo- del obispo [Ávalos], que con sus particulares contrataciones tenía ocupados los clérigos, repartiéndoles coca a cada uno para que se la vendiesen en los pueblos de sus doctrinas entre los indios: en efecto esto se había de hacer, quisiesen o no quisiesen. Y en otras partes les repartían lana para costales, y para ropa de la tierra que visten los indios; y esto asimismo se había de hacer porque lo pedía rogando -o por su persona o por sus cartas-el "sobrino" del obispo; y el rogar era de modo que era más peligroso dejar de obedecer su ruego que desobedecer el mandato de otro perlado. Porque, si no se hacía lo que el "sobrino" del obispo quería, luego era puesto el sacerdote en el número de los delincuentes del crimen para en la primera visita. $Y$ algunas veces no se tardaba tanto, porque cuando un receptor lo enviaban a visitar, por cualquiera pequeña queja tenía riesgo de ser destruido, porque no molestó a los indios ocupándolos en hacer la hacienda del "sobrino" del obispo. (Álvarez, 1998[1588]: 54)

Al mismo tiempo, el clérigo Álvarez acusaba a Granero de Ávalos de distribuir mercancías de Nueva España, traídas por él, en el mercado de Potosí. Esta operación demandaba gran cantidad de esfuerzo local:

[...] no le bastaban los clérigos de las provincias de Pacasas [Pacajes] y Carangas: echándolos a todos por cabezas, contribuían ganado para trajinar más de cincuenta mil ducados de ropa, que trajo de Nueva España para vender; algunos, no queriendo acudir, se escapaban de esta carga en aventura de su daño. (Álvarez, 1998[1588]: 53)

Ambas iniciativas impactaban en las decisiones que tomaban los clérigos como doctrineros, ya que, la población indígena proporcionaba productos, transporte, mano de obra y consumo al movimiento económico del obispo. Como se señaló, la negociación y coordinación entre doctrineros e indígenas fue fundamental para mantener estos flujos económicos.

La avalancha de solicitudes de pago tras el fallecimiento de Granero de Ávalos, mencionado anteriormente, muestra en parte las formas de financiamiento que manejaba el prelado. El testimonio de Álvarez incluye a la clerecía doctrinera como afectada, quienes aprovecharon la oportunidad para obtener del obispo algo a cambio por medio de préstamos. Hubo casos en que "se perdieron del todo", por prestar lo poco que tenían, no lograr beneficios económicos tras su apoyo a los "trajines" del obispo o bien, por miedo a cobrar lo adeudado (Álvarez, 1998[1588]: 55).

Conjugando los rastros de la primera parte de este escrito sobre el gobierno del obispo Granero de Ávalos, el texto de Álvarez permite trazar la impronta del obispo en la diócesis, destacando la influencia económica y política que ejerció sobre los clérigos y las parroquias locales de Charcas. A continuación, presentamos el caso de Álvarez como muestra del impacto en la trayectoria de los clérigos doctrineros. 


\section{Los conflictos de Bartolomé Álvarez durante el gobierno de Granero de Ávalos}

Según los registros de la Caja Real de Potosí, Bartolomé Álvarez ejerció como doctrinero en Sabaya junto a Florián Cortina en 1581. Para el cuidado de la doctrina, la tasación de Toledo (1573) dispuso de 3.000 pesos en sínodos, distribuidos entre Chuquicota y Sabaya: 2.800 pesos repartidos en tres sacerdotes residentes en los pueblos y 200 para la doctrina de los mitayos en Potosí (Cook, 1975:19). Álvarez y Cortina recibieron 175 pesos cada uno por seis meses de doctrina en Sabaya durante el último semestre del año, alternando el trabajo: "sirvieron la dicha doctrina cada uno dellos cierto tiempo del dicho tiempo como de sus cartas de pago parece". A comienzos de 1582, Álvarez y Francisco Trejo fueron titulares de la dicha doctrina hasta fines de junio, recibiendo 350 pesos cada uno[15].

Esta primera etapa de Álvarez como doctrinero estuvo marcada por las exigencias económicas del gobierno del obispo Granero de Ávalos, lo que afectó el desenvolvimiento del clérigo en la diócesis.

Antes del término del año 1582, entre agosto y septiembre (Villarías y Martín Rubio, 1998: XX), Álvarez se enfrentó al cobro de la "cuarta de pago", autorizada por la Corona en beneficio del recién arribado obispo. Álvarez lo llamó “cuarta de cinco años", siendo saldada por los doctrineros (Álvarez, 1998[1588]: 62).

Al llegar el visitador Francisco Hidalgo y el notario Jerónimo Venegas, Álvarez habría intentado pactar con ellos alguna rebaja del pago, aludiendo a su precariedad económica:

[...] no sobre si la había de pagar [...] el debate fue sobre que yo, desabrido de muchas injusticias de las que he contado [no propias], había estado mucho tiempo sin doctrina, y en aquella sazón había poco que estaba ocupado, y pobre. (Álvarez, 1998[1588]: 62).

Este hecho debió ser uno de los motivos para arremeter en su escrito contra los visitadores eclesiásticos, quienes, además de presionar económicamente a los doctrineros, eran intransigentes en la ejecución de órdenes diocesanas.

Al ver pocas posibilidades de negociación, cuestionó el origen y las ambigüedades del cobro al visitador, sin tener respuesta. Tras este conflicto, Álvarez acusa que se le quitó la doctrina “porque pequé en ser bachiller” (Álvarez, 1998[1588]: 62), aludiendo irónicamente el haber procedido como "agudo hablador y sin fundamento" (Covarrubias, 1611: 221).

Este hecho acarreó un segundo episodio relacionado con los ingresos económicos del clérigo, esta vez enfrentado a los principales de Sabaya. En los registros de la Caja de Potosí se consigna el hecho. Álvarez se ausentó tres meses de Sabaya, posiblemente por la suspensión anterior, volviendo en diciembre para cobrar a la parroquia su labor como doctrinero. Sin embargo, los caciques le entregaron solo la mitad del estipendio. Irritado, presionó violentamente a los caciques “metiéndolos en una casa y los tapió y encerró en ella y tuvo presos muchos días [...] quitándoles la 
comida y bebida". Los principales mantuvieron su decisión "por no habérselo mand[ad]o su corregidor [Juan Zapata] le pagasen[,] no estaban obligados a ello". Al ceder, pagaron de su hacienda la mitad del sínodo solicitado por Álvarez y no de la caja de comunidad, como estaba establecido. El documento señala que, tras el pago, Álvarez "se fue por mandado del concilio a la ciudad de Los Reyes diciendo ser fraile". El corregidor Zapata se hizo cargo de la denuncia, reuniendo testimonios de indígenas, sacerdotes y "otros comarcanos", para conseguir que la Audiencia les restituyera el dinero directamente a los caciques[16].

Esta acción pudo responder a la deuda con el obispado por la "cuarta" del obispo Granero de Ávalos, como sugiere Villarías y Martín Rubio (1998: XX). Ahora bien, no podemos asegurar que Álvarez participó del Concilio Limense de 1583, ni que fue convocado, aunque, menciona haber estado en Lima en aquel año (Álvarez, 1998[1588]: 234). Sí debió ser atrayente la idea de visitar la sede arzobispal, tras su mala experiencia en Sabaya. Cabe subrayar la mención de los caciques a que el clérigo habría ido al concilio "diciendo ser fraile". Esto podría haber significado una ironía del propio Álvarez, considerando su animadversión por los religiosos y el rol que jugaron en la reunión episcopal.

Luego de este hecho, el clérigo Álvarez se vio afectado por el mecanismo de financiamiento para sustentar el proceso de apelación al Tercer Concilio, aprobado por el obispo Granero de Ávalos y vicarios locales a fines de 1584 . Recordemos que el acuerdo estipuló el pago de 30 pesos por doctrina, exigiendo rigurosidad en su cobro.
Álvarez acusó que le fue solicitado el importe sin tener beneficio eclesiástico, posiblemente, durante el año de 1585, negándose a colaborar en provecho de un "criado" del obispo, en referencia a Domingo de Almeyda. Como castigo fue "preso y descomulgado, estando muy pobre y sin doctrina" durante cinco años.

Además, acusa una instrumentalización del cobro por parte del obispo:

Y así, mandó [Granero de Ávalos] que se cobrasen de los curas y de los que no tenían doctrinas, porque sabía que había algunos clérigos que querían más morir de hambre que no irle a cohechar ni a pedir doctrina, por no verse tratar de la suerte que trataba a todos. Y así me sucedió a mí ponerme preso y descomulgado, estando muy pobre y sin doctrina en el tiempo que he dicho [cinco años], hasta que por redimir mi vejación empeñé una fuente de plata de Francisco de Montalvo, alguacil mayor de Potosí, en los jueces del obispado hasta que pude pagar. (Álvarez, 1998[1588]: 62)

Esta declaración de Bartolomé Álvarez muestra la intransigencia en el cobro, aunque, en 1593 algunos canónigos del obispado no reconocieron la provisión de pago estipulada por el obispo Ávalos[17]. Para volver a la actividad, Álvarez recurrió a sus redes personales con autoridades en el centro económico potosino, empeñando "una fuente de plata de Francisco de Montalvo, alguacil mayor de Potosí, en los jueces del obispado hasta que pude pagar" (Álvarez, 1998[1588]: 62). El objeto de pago mencionado, quizá, también fue 
una ironía, si tomamos en cuenta su denuncia de codicia entre los encargados del obispado.

La primera etapa de Bartolomé Álvarez como doctrinero, entre 1580 y 1582 , estuvo cargada de conflictos con la autoridad diocesana. Se constata que la agenda del prelado impactó en la trayectoria de Álvarez, debilitando su estabilidad como clérigo beneficiado hasta provocar su salida de las doctrinas. No deja de ser importante que la solicitud de redención fue acogida por el Cabildo Eclesiástico, una vez fallecido Granero de Ávalos. Álvarez volverá a ocupar una doctrina en Aullagas hacia 1586, cuando el obispado se encontraba en Sede Vacante. Dos años después, en julio, daba por finalizado su memorial.

Quizá como recurso literario o el impacto de una realidad compleja, Álvarez comentaba al Rey su determinación de dejar las doctrinas. Una de sus razones era económica: "suplico no se me mande ir a España [a dar cuenta de lo escrito][...] por no haber hecho mi hacienda y porque, para hacerla -si pudiere-, quiero dejar las doctrinas" (Álvarez, 1998[1588]: 308). Como hemos visto, Álvarez no logró asentarse económicamente en una doctrina, aunque, tenía en mente la comercialización como parte del quehacer y beneficio de una parroquia. Leemos esta frustración desde el impacto que generó el gobierno del obispo Granero de Ávalos entre los clérigos.

Factores pastorales también intervinieron en su decisión. Álvarez no logró sobreponerse a la dinámica devocional que estaba viviendo la sociedad indígena del obispado, una mezcla de elementos cristianos y andinos en respuesta a la convulsión colonial (Abercrombie, 2006: cap. VI; Castro, 2008). Tampoco pudo responder a los cambios que se estaban experimentando al interior de los ayllus contra la imposición laboral ni al juego de legitimidades de sus líderes étnicos (Saignes, 1981, 1987; Morrone 2013). Destacaba como motivos la permisividad de los sacerdotes, autoridades eclesiásticas, civiles y, además, los episodios de violencia contra los clérigos perspicaces (Álvarez, 1998[1588]: 18, 132). Poco a poco, Álvarez fue resistiéndose a distribuir sacramentos y reconocer avances cristianos en sus feligreses, concluyendo finalmente "no doctrinar ni ser cura de indios” (Álvarez, 1998[1588]: 262).

\section{Conclusiones}

En este artículo hemos explorado las repercusiones locales del gobierno del obispo de Charcas Alonso Granero de Ávalos, presentando el escrito del clérigo Bartolomé Álvarez como testimonio local del impacto en las parroquias indígenas y los clérigos doctrineros.

Para lograr sus objetivos, hemos observado cómo el prelado buscó mantener un flujo económico hacia sus arcas apoyado por sus familiares, con distinto éxito, controlando las designaciones de beneficios eclesiásticos e instrumentalizando sus potestades episcopales para asegurar la participación de los clérigos en sus redes comerciales. Las solicitudes de ingresos previos a la toma de posesión, el control de las doctrinas y la diseminación de negocios familiares con cargo a los clérigos, fueron parte de sus estrategias. Estas actividad económica del prelado, junto a las medidas tributarias de su gobierno (como el alza de 
impuesto a la pila bautismal y el financiamiento de las apelaciones), demandaban productos y mano de obra en las parroquias indígenas. Esta situación generó conflictos al interior de las doctrinas, cuya resolución varió según la capacidad de adaptación de los clérigos a las autoridades eclesiásticas e indígenas.

Hemos propuesto el testimonio y trayectoria de Bartolomé Álvarez como reflejo de los conflictos e impactos provocados por Granero de Ávalos. Los intereses y expectativas económicas del clérigo chocaron tempranamente con las medidas pecuniarias del obispo. El episodio de Sabaya es parte de las consecuencias derivadas a la población indígena, lo que, junto a la decisión final de Álvarez, habrían sido episodios recurrentes en la diócesis de Charcas.

¿Cuántos Álvarez más habrán visto sus expectativas truncadas por las autoridades episcopales? ¿Hasta qué punto influyeron los intereses externos en las decisiones económicas y pastorales de los doctrineros? y, ¿cómo se habrá expresado en otras áreas de la diócesis? Son problemas que surgen de este estudio como guía de lectura documental e interpretativa.

\section{Referencias citadas}

Abercrombie, T. (2006): Caminos de la memoria y del poder: etnografía e historia en una comunidad andina, La Paz, Institut français d'études andines - Instituto de Estudios Bolivianos.

Acosta, A. (1982): “Los clérigos doctrineros y la eco- nomía colonial (Lima, 1600-1630)", Allpanchis 14(19), pp. 117-149.

Acosta, A. (1987): “Francisco de Ávila (Cusco 1573(?) - Lima 1647)", en G. Taylor, Ritos y Tradiciones de Huarochirí, Lima, Instituto de Estudios Peruanos, Instituto Francés de Estudios Andinos, pp. 551-616.

Acosta, A. (2016): “Iglesia, intereses económicos y teología de la dominación. Contradicciones en la evangelización de la América Española. Perú, siglo XVI", Diálogo Andino 49, pp. 3-17.

Albó, X. (1999): “Un clérigo muy particular ante los indios de Charcas (Bolivia) y su memorial de 1588 recién publicado", Revista de Dialectología y tradiciones populares LIV (1), pp. 189-206.

Álvarez, B. (1998[1588]): De las costumbres y conversión de los indios del Perú. Memorial a Felipe II (1588), Madrid, Ediciones Polifemo.

Álvarez, M. (2015): “Ellargo camino a la secularización en el arzobispado de México", en La secularización de doctrinas y misiones en el Arzobispado de México 17491789, México D.F., Universidad Nacional Autónoma de México, pp. 23-86.

André, M., Romo, J. y Pastora, I. (1847-1848): Diccionario de derecho canónico arreglado a la jurisprudencia eclesiástica española antigua y moderna (4 tomos), Madrid, Imprenta de D. José de la Peña.

Assadourian, C. (1982): El sistema de la economía colonial. Mercado interno, regiones y espacio económico, Lima, Instituto de Estudios Peruanos. 
Bakewell, P. (1989): Mineros de la Montaña Roja. El trabajo de los Indios en Potosí 1545-1650, Madrid, Alianza Editorial.

Battcock, C. (2015): “Para el fin que el demonio pretende: el baile y el temblor, un mal a erradicar en los Andes", Perspectivas Latinoamericanas, pp. 56-68.

Cadau, M. L. (1998): "Instrumentos de modelación y control: El Concilio de Trento y las visitas pastorales (la archidiócesis hispalense, 1548-1604)", Congreso Internacional "Felipe II (1598-1998), Europa dividida, la monarquía católica de Felipe II”, III, pp. 159-177.

Carmagnani, M. (2004): “Review: una institución económica colonial: repartimiento de mercancías y libertad de comercio", Historia Mexicana, 54(1), pp. 249-262.

Castro, N. (2008): "Y le tuviesen por santo. Caminos de la devoción indígena colonial (Audiencia de Charcas, 1708)”, Diálogo Andino 31, pp. 7-29.

Castro, N. (2021): "Prestigio simbólico y control episcopal. La estrategia del obispo Alonso Ramírez de Vergara frente al capítulo catedralicio de Charcas", Diálogo Andino [en prensa].

Cook, N. (1975): Tasa de la visita general de Francisco de Toledo, Lima, Universidad Nacional Mayor de San Marcos.

Cordero, M. (2016): Institucionalizar y desarraigar. Las visitas idolátricas en la diócesis de Lima, siglo XVII, Lima, Pontificia Universidad Católica del Perú - Instituto Riva Agüero - Universidad Adolfo Ibáñez.
Covarrubias, S. de (1611): Tesoro de la lengua castellana o española, Madrid, Luis Sánchez.

Cunill, C. (2011): “El indio miserable: nacimiento de la teoría legal en la América colonial del siglo XVI”, Cuadernos Inter.c.a.mbio 9, pp. 229-248.

Domínguez, F. (2011): “La Inquisición española y los indios", en Oesterreicher, W. y Schmidt-Riese, R., eds., Esplendores y miserias de la evangelización de América. Antecedentes europeos y alteridad indígena, Berlín, Degruiter, pp. 45-71.

Duviols, P. (1977): La destrucción de las religiones andinas (conquista y colonia), México D.F., Universidad Nacional Autónoma de México.

Encina, D. (1945): Cedulario Indiano, III vols., Madrid, Ediciones Cultura Hispánica.

Enciso, J. (ed.) (2005): Cedulario de la Audiencia de La Plata de Los Charcas (siglo XVI), Sucre, Archivos y Bibliotecas Nacionales de Bolivia.

Galdames, L. y Álvarez, L. (2001): “El soporte cultural que sustenta el discurso de Bartolomé Álvarez”, Diálogo Andino 20-21, pp. 73-80.

García, J. (1964): Historia de la Iglesia en La Plata. Tomo I. La Iglesia durante la colonia (desde 1533 a 1700), Sucre, Archivo-Biblioteca Arquidiocesanos Monseñor Taborga.

Guibovich, P. (1991): “Cristobal de Albornoz y el taki onqoy”, Historica XV (2), pp. 205-236. 
Hidalgo, J. (2011): “Redes eclesiásticas, procesos de extirpación de idolatrías y cultos andinos coloniales en Atacama. Siglos XVII y XVIII", Estudios Atacameños 42, pp. 183-237.

Hidalgo, J., Marsilli, M., y Aguilar, J. (2016): “Redes familiares, carreras eclesiásticas y extirpación de idolatría: doctrina de Camiña, Tarapacá. Siglo XVII", Chungara 48(3), pp. 409-428.

Irigoyen, A. (2008): “Un obispado para la familia: Francisco Verdín Molina, prelado de Guadalajara y Valladolid en la segunda mitad del sigloXVII", Historia Mexicana LVIII(2), pp. 557-594.

Kermele, N. (2009): “L'hétérodoxie indigène au cœur des conflits intrasociaux dans le Pérou colonial: perception et analyse de Bartolomé Álvarez, doctrinero de la fin du XVIème siècle”, Nuevo Mundo Mundos Nuevos [En línea]. URL: https://journals.openedition. org/nuevomundo/56562?lang=es

Lavallé, B. (1982): “Las doctrinas de indígenas: núcleos de explotación colonial (siglos XVI-XVII)", Allpanchis 14(19), pp. 151-171.

Le Goff, J. (2013): La Bolsa y la vida: economía y religión en la Edad Media, Barcelona, Gedisa.

Levillier, R. (1922): Audiencia de Charcas. Correspondencia de presidentes y oidores. Documentos del Achivo de Indias, III vol., Madrid, Imprenta de Juan Pueyo.

Levillier, R. (1924): Gobernantes del Perú. Cartas y papeles. Siglo XVI, vol. VI, Madrid. Imprenta de Juan Pueyo.
Lisi, F. (1990): El Tercer Concilio Limense y la aculturación de los indígenas sudamericanos. Estudio crítico con edición, traducción y comentario de las actas del concilio provincial celebrado en Lima entre 1582 y 1583, Salamanca, Ediciones Universidad de Salamanca.

Lopez de Ayala, I. (1785[1564]): El sacrosanto y ecuménico Concilio de Trento, Madrid, Imprenta Real.

Marsilli, M. (2005): “"I heard It through the grapevine": analysis of an anti-secularization initative in the Sixteenth-Century Arequipan Countryside, 15841600", The Americas, 61(4), pp. 647-672.

Marsilli, M. (2014): Hábitos perniciosos: religión andina colonial en la diócesis de Arequipa (siglos XVI al XVIII), Santiago, Dirección de Bibliotecas Archivos y Museos DIBAM - Centro de Investigaciones Barros Arana.

Martín Rubio, M. (1997): “Costumbres de los indios del Perú. Un temprano antecedente de la política de extirpación de idolatrías en el virreinato peruano", Boletín del Instituto Riva-Agüero 24, pp. 295-308.

Martín Rubio, M. (2000): "La mujer indígena andina, según un memorial inédito dirigido a Felipe II en 1588", Revista del Archivo Regional del Cusco 165, pp. 1506-1514.

Medina, J. T. (1887): Historia del tribunal del Santo Oficio de la Inquisición de Lima (1569-1820), Santiago, Imprenta Gutemberg.

Medina, J. T. (1952): Historia del Tribunal del Santo Oficio de la Inquisición en México, 2da. ed., México D.F., Ediciones Fuente Cultural. 
Millones, L. (2007): “Sentencia del Concilio Provincial de Lima en favor de Cristóbal de Albornoz", en Taki onqoy: de la enfermedad del canto a la epidemia, Santiago, Centro de Investigaciones Diego Barros Arana, pp. 321-326.

Monsalve, M. (2003): “Curacas pleitistas y curas abusivos. Conflicto, prestigio y poder en los Andes Coloniales Siglo XVII”, en Cahill, D. y Tovías, B., Élites indígenas en Los Andes. Nobles, caciques y cabildantes bajo el yugo colonial, Quito, Ediciones Abya-Yala.

Morgado, A. (2000): Ser clérigo en la España del Antiguo Régimen, Cádiz, Servicio de Publicaciones de la Universidad de Cádiz.

Morrone, A. (2013): "Curas doctrineros y caciques andinos en la construcción de legitimidades: las iglesias rurales de La Paz, Audiencia de Charcas, 1570-1630", Jahrbuch für Geschichte Lateinamerikas 50, pp. 29-54.

Morrone, A. (2017): “El lago de los curas. Mediación sociopolítica y cultural en los corregimientos del lago Titicaca (1570-1650)", Estudios Atacameños 55, pp. 183-202.

O’Phelan, S. (1988): Un siglo de rebeliones anticoloniales. Perú y Bolivia (1700-1783), Cuzco, Centro Bartolomé de Las Casas.

Pease, F. (1969): "Visita del obispado de Charcas antes de 1590", Revista Humanidades Pontificia Universidad Católica del Perú 3, pp. 89-125.

Piho, V. (1977): “La secularización de las parroquias y la economía eclesiástica en la Nueva España”, Journal de la Société des Américanistes 64, pp. 81-88.
Querejazu, R. (1995): Historia de la Iglesia católica en Charcas (Bolivia), La Paz, Conferencia Episcopal Boliviana.

Quisbert, P. (2015): “La construcción y consolidación del orden colonial (1570-1600)", en Bridikhina, E., coord., Bolivia, su historia. Tomo II. La experiencia colonial en Charcas s. XVI-XVII, Bolivia, Coordinadora de Historia, pp. 169-216.

Ramos, G. (1992): “Política eclesiástica y extirpación de la idolatría: discursos y silencios en torno al Taqui Onqoy”, Revista Andina, 10(1), pp. 147-169.

Ramos, G. (2016): “Pastoral Visitations: Spaces of Negotiation in Andean Indigenous Parishes", The Americas, 73(1), pp. 39-57.

Ramos, G. (2019): “Los sujetos en la visita pastoral: una mirada a la micropolítica colonial andina)”, Anuario de Historia de la Iglesia, 28, pp. 133-146.

Real Academia Española (RAE) (1726): Diccionario de la lengua castellana, Madrid, Imprenta de Francisco del Hierro.

Real Academia Española (RAE) (1770): Diccionario de la lengua castellana compuesto por la Real Academia Española, Madrid, Joaquín Ibarra.

Real Academia Española (RAE) (1791): Diccionario de la lengua castellana compuesto por la Real Academia Española, Madrid, Viuda de Joaquín Ibarra.

Recopilación de leyes de los reinos de las Indias (1681), Madrid, Ivlian de Paredes. 
Regalado, L. (2008): “Culpa y mala naturaleza: religiosidad y rituales andinos en el Memorial (1588) de Bartolomé Álvarez”, Histórica 2(32), pp. 6-31.

Saignes, T. (1984): "Las etnias de Charcas frente al sistema colonial (siglo XVIII). Ausentismo y fugas en el debate sobre la mano de obra indígena, 1595-1665", Jahrbuch für Geschichte Lateinamerikas 21, pp. 27-75.

Saignes, T. (1987): “De la borrachera al retrato: los caciques andinos entre dos legitimidades (Charcas)", Revista Andina 9(1), pp. 139-170.

Sala, B. (1858): Manual de Erudición sagrada y eclesiástica ordenado en forma de Diccionario, Barcelona, Librería Religiosa.

Suess, P. (2002): La conquista espiritual de la América española. 200 documentos. Siglo XVI, Quito, Ediciones Abya-Yala.

Traslosheros, J. (2002): “El tribunal eclesiástico y los indios en el Arzobispado de México, hasta 1630”, Historia Mexicana, LI(3), pp. 486-516.

Vallejo, J. (2001): “La inquisición del Distrito de la Audiencia de Guatemala (1569-1609)", Anuario de Historia del Derecho Español 71, pp. 161-266.

Vargas Ugarte, R. (1951): Concilios Limenses (15511776), vol. I., Lima.

Vargas Ugarte, R. (1952): Concilios Limenses (15511776), vol. II, Lima.
Vargas Ugarte, R. (1959): Historia de la Iglesia en el Perú. Burgos: Imprenta de Aldecoa.

Villarías, J. y Martín Rubio, M. (1998): “Sobre el autor”, en Álvarez, B., De las costumbres y conversión de los indios del Perú. Memorial a Felipe II (1588), Madrid, Ediciones Polifemo, pp. XIII-XXIII.

\section{Notas}

[1] "Nombramiento de Alonso Granero de Avalos", 11.04.1573. AGI (Archivo General de Indias), CONTRATACION,5788,L.1, fs. 71-72

[2] "Real cédula concediendo al licenciado Granero de Ávalos licencia[...]”, 31.05.1576. AGI, MEXICO,1090,L.8, fs. $156 \mathrm{v}-157 \mathrm{r}$

[3] "Cartas de cabildos seculares", 15.10.1576. AGI, GUADALAJARA,30,N.16

[4] "Real cédula dando la razón a los oficiales de la Real Hacienda[...]", 19.04.1583. AGI, MEXICO,1064, L.2, fs.110r-111r.

[5] "Competencias entre el Tribunal de la Inquisición de México y el obispo de La Plata”, 1581-1582. AGI, INQUISICIÓN,1734, Exp.1.

[6] "Real Cédula al deán y Cabildo, sede vacante, de la iglesia catedral del obispado de Charcas”, 30-10-1578. AGI, CHARCAS,415,L.1, fs. 26r-26v; "Real Provisión al virrey y demás autoridades de las provincias del Perú”, 05.03.1579. AGI, CHARCAS, 415, L.1, fs. 40v-41r.

Vargas Ugarte, R. (1954): Concilios Limenses (1551-1776), vol. III Historia, Lima. 
[7] Archivo Catedralicio Metropolitano de Lima (ACML), Diligencias $\mathrm{n}^{\circ} 20$, fs. $15-22 \mathrm{v}$.

[8] ACML Diligencias nº 20, f. 14.

[9] ACML Diligencias nº 20, fs. 8-13v.

[10] ACML Diligencias nº 20, fs. 46-66.

[11] "Obligación de pago de Luis Delgado y Bartolomé Álvarez a favor de Francisco Martínez. 30-XI-1579”, Archivo y Biblioteca Nacionales Boliviano (ABNB) EC 32, fs. $145 \mathrm{r}-145 \mathrm{v}$. Agradecemos al Dr. Nelson Castro Flores por rescatar este rastro de Álvarez.

[12] Avieso: "lo que no va por vía derecha, como la saeta, que dio el golpe fuera del blanco, y al mozo que no camina por la vía derecha de la virtud llamamos avieso" (Covarrubias, 1611: 104).

[13] Dolames: "ages o enfermedades ocultas que suelen tener las caballerías" (RAE Usual, 1791: 344). Ages: "Los achaques o males habituales" (RAE Autoridades, 1770: 96).

[14] ACML Diligencias nº20, f.10r

[15] "Descargo de lo que se ha pagado a los curas[...]". AHCNMP (Archivo Histórico de la Casa Nacional de Moneda Potosí) CR 444: fs. 62v-63r.

[16] ACNMP Caja Real 444, f.64-64v. Este documento se encuentra transcrito en el estudio de Villarías y Martín Rubio (1998: XX-XXI).

[17] ACML Diligencias no 20: f. 6v 